Espinosa, A., Zock, J.P., Benavente, Y., Boffetta, P., Becker, N., Brennan, P., Cocco, P., Foretova, L., Maynadié, M., Staines, A., Nieters, A., Kogevinas, M., Sanjose, S. de. Occupational exposure to immunologically active agents and risk for lymphoma: the European Epilympa 7 case-control study. Cancer Epidemiology: 2013, 37(4), 378-384

\begin{tabular}{|l|l|}
\hline $\begin{array}{l}\text { Postprint } \\
\text { Version }\end{array}$ & 1.0 \\
\hline Journal website & http://linkinghub.elsevier.com/retrieve/pii/S1877-7821(13)00029-5 \\
\hline Pubmed link & http://www.ncbi.nlm.nih.gov/pubmed/23522435 \\
\hline DOI & 10.1016/j.canep.2013.02.006
\end{tabular}

This is a NIVEL certified Post Print, more info at http://www.nivel.eu

\title{
Occupational exposure to immunologically active agents and risk for lymphoma: The European \\ Epilymph case-control study
}

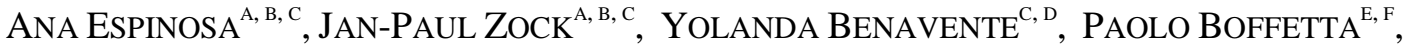 \\ NiKOlaus BeCKeR ${ }^{\mathrm{G}}$, PAUl BRENNAN ${ }^{\mathrm{H}}$, PIERLUigi COCCO ${ }^{\mathrm{I}}$, LENKA FORETOVA', MARC

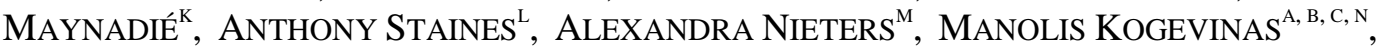 \\ SILVIA DE SANJOSE, D, \\ ${ }^{a}$ Centre for Research in Environmental Epidemiology (CREAL), Barcelona, Spain \\ ${ }^{\mathrm{b}}$ IMIM (Hospital del Mar Medical Research Institute), Barcelona, Spain \\ ${ }^{c}$ CIBER Epidemiología y Salud Pública (CIBERESP), Barcelona, Spain \\ d Unit of Infections and Cancer (UNIC), Cancer Epidemiology Research Programme, Institut \\ Català d' Oncologia - Catalan Institute of Oncology, IDIBELL, L' Hospitalet de Llobregat, \\ Barcelona, Spain \\ e Tisch Cancer Institute and Institute for Translational Epidemiology, Mount Sinai School of \\ Medicine, New York, United States \\ ${ }^{f}$ International Prevention Research Institute, Lyon, France \\ ${ }^{9}$ Division of Cancer Epidemiology, German Cancer Research Center, Im Neuenheimer Feld \\ 280, D-69120 Heidelberg, Germany \\ ${ }^{\mathrm{h}}$ IARC, International Agency for Research on Cancer, Lyon, France \\ i Department of Public Health, Occupational Health Section, University of Cagliari, Italy \\ ${ }^{j}$ Cancer Epidemiology \& Genetics, Masaryk Memorial Cancer Institute, Brno, Czech \\ Republic \\ ${ }^{k}$ Biological Hematology Unit, CRB Ferdinand Cabanne, Universitary Hospital of Dijon and \\ EA4184, University of Burgundy, France \\ 'Public Health University College, Dublin, Ireland \\ ${ }^{\mathrm{m}}$ Centre of Chronic Immunodeficiency, Molecular Epidemiology, University Medical Center \\ Freiburg, Freiburg, Germany \\ ${ }^{\mathrm{n}}$ National School of Public Health, Athens, Greece
}

\begin{abstract}
Objectives: Allergies and asthma may be protective for the development of lymphoma. We evaluated whether occupational allergens that provoke immune reactivity and asthma through an IgE-mediated pathway are protective for lymphoma.

Methods: The Epilymph study includes histologically or cytologically confirmed Hodgkin, B-cell, and T-cell lymphoma cases from six European countries (Spain, France, Germany, Italy, Ireland, and Czech Republic) recruited in 1998-2004. Controls were frequency matched to cases by age, gender, and study centre. Lifetime occupational exposure to seven high molecular weight
\end{abstract}


Espinosa, A., Zock, J.P., Benavente, Y., Boffetta, P., Becker, N., Brennan, P., Cocco, P., Foretova, L., Maynadié, M., Staines, A., Nieters, A., Kogevinas, M., Sanjose, S. de. Occupational exposure to immunologically active agents and risk for lymphoma: the European Epilympa case-control study. Cancer Epidemiology: 2013, 37(4), 378-384

(HMW) agents was evaluated through an asthma-specific job-exposure matrix. 2205 lymphoma cases and 2296 controls with complete occupational history could be included in the analysis. Associations between HMW exposures and lymphoma were evaluated using pooled unconditional logistic regression analyses.

Results: Individuals exposed to HMW agents had a non-statistically significant decreased risk of any lymphoma (OR, 0.88: 95\% CI, 0.74-1.05) and of B-cell lymphoma (OR, 0.91; 95\% CI, 0.76-1.09), and a significantly decreased risk for Hodgkin lymphoma (OR, 0.62; 95\% CI, 0.40-0.98). A decrease in risk for lymphoma was found for exposure to latex (OR, 0.74; 95\% CI, 0.55-0.99).

Conclusions: Further epidemiologic and mechanistic research is needed to confirm that occupational exposure to HMW agents predisposing to asthma can reduce the risk of lymphoma.

\section{INTRODUCTION}

The role of the immune system in the aetiology of non-Hodgkin lymphoma (NHL) has been demonstrated by the excess risk among immunosuppressed patients and also in situations of chronic immunostimulation, due to bacterial and viral infections ${ }^{[1]}$. A decreased risk of haematological malignancies has been observed among asthma patients in several studies suggesting an immunological link between both diseases [2], [3], [4], [5], [6], [7] and [8]. Atopic asthma is typically associated with a deregulated Th2-biased immune response including the production of B cellstimulatory cytokines, such as IL-4 and IL-13 ${ }^{[9]}$ and [10]. Asthma is associated with high IgE levels. Interestingly, total and specific IgE to common aeroallergens have been shown to be inversely associated with risk of lymphoma in some studies ${ }^{[11]}$. However, the fact that in a small prospective study this association was observed close to the time of diagnosis, was interpreted as a possible reverse causality in which NHL suppresses the immunologic response to allergens ${ }^{[12]}$. Some casecontrol studies have suggested a link between asthma and lymphoma, but the potential concern in these studies is that the onset of the disease may change IgE levels.

In a preliminary analysis of the Spanish arm of the international Epilymph casecontrol study on lymphoma, we evaluated whether occupational exposure to high molecular weight (HMW) agents that are associated with asthma ${ }^{[13]}$ and that act predominantly through an IgE-dependent allergic mechanism ${ }^{[14]}$, were also associated with risk for specific NHL types ${ }^{[15]}$. That analysis showed that exposure to HMW agents may lead to a decreased risk of all lymphomas, particularly B-cell lymphoma, and to an increased risk for Hodgkin lymphoma. In 2009, a large casecontrol study in Italy using a similar approach also identified a reduced risk of lymphoma associated with exposure to agents related to occupational asthma ${ }^{[16]}$. In this analysis we incorporate data from studies in six countries participating in the international Epilymph consortium following the same protocol. We evaluated 
Espinosa, A., Zock, J.P., Benavente, Y., Boffetta, P., Becker, N., Brennan, P., Cocco, P., Foretova, L., Maynadié, M., Staines, A., Nieters, A., Kogevinas, M., Sanjose, S. de. Occupational exposure to immunologically active agents and risk for lymphoma: the European Epilympa 7 case-control study. Cancer Epidemiology: 2013, 37(4), 378-384

whether lifetime occupational exposure to HMW agents capable of inducing IgEmediated allergic sensitization is associated with the risk of specific lymphoma subtypes ${ }^{[17]}$, aiming to reduce with this analysis the potential effect of a reverse causality mechanism.

\section{MATERIALS AND METHODS}

\subsection{Study design and participants}

The Epilymph study is a multicenter case-control study including populations from 6 European countries (Germany, Italy, Spain, Ireland, France and Czech Republic). Newly diagnosed cases of lymphoid neoplasms and controls were recruited from 1998 to 2004 using a common core protocol and interview in all countries. The diagnosis of lymphoma was verified by histology and 99\% of them were supplemented by immunohistochemistry test and flow cytometry. Cases were categorized according to the WHO Classification for Neoplastic Diseases of the Lymphoid Tissues ${ }^{[18]}$. Subjects with a diagnosis of uncertain malignant potential such as post-transplant lymphoproliferative disorder or monoclonal gammapathies of undetermined significance were excluded. Controls were identified at same time as the diagnosis of the cases and were sampled from the general population based on census lists in Italy and Germany matched by age and sex. In the other 4 countries, controls were recruited from the same hospital as the cases and were frequency matched to cases by age, gender, and hospital. Individuals with organ transplantation, HIV or a diagnosis of a systemic infection were excluded by protocol [19] and [20]; for our study, controls hospitalized due to respiratory diseases were also excluded. We further excluded subjects who reported to have never worked. Finally, the study includes 2205 lymphoma cases and 2296 controls with complete information of the exposure and adjustment variables $\left({ }^{\text {Fig. }}{ }^{1}\right.$ ). Informed consent was obtained from all participants in accordance to guidelines from the institutional review boards of the participating institutes.

\section{[FIGURE 1]}

\subsection{Questionnaire and occupational history}

Information was requested through a structured face-to-face interview. The same structured questionnaire was used and translated into the local language in each country. Questions collected information on socio-demographic factors, reproductive, familial and medical history including allergies and asthma, residence, tobacco, alcohol and drugs consumption, use of hair dyes, sunlight exposure and complete occupational history. Lifetime occupational history was recorded including all jobs held for at least one year including a job and industry description and start and end years.

\subsection{Occupational exposure assessment}

Occupations were coded in each country using the 1968 International Labour Office International Standard Classification of Occupations (ISCO-68) ${ }^{[21]}$. ISCO-68 uses a five-digit hierarchical system that classifies jobs into 1506 occupational titles and is 
Espinosa, A., Zock, J.P., Benavente, Y., Boffetta, P., Becker, N., Brennan, P., Cocco, P., Foretova, L., Maynadié, M., Staines, A., Nieters, A., Kogevinas, M., Sanjose, S. de. Occupational exposure to immunologically active agents and risk for lymphoma: the European Epilympa 7 case-control study. Cancer Epidemiology: 2013, 37(4), 378-384

published in English, French, and Spanish. Codes of all jobs for each participant were linked to an asthma-specific job exposure matrix (OAJEM) that had been adapted to the ISCO-68 coding system ${ }^{[15]}$. The OAJEM includes protein exposures such as latex, flour, biological enzymes and mites that are known to produce asthma through an IgE mediated mechanism ${ }^{[13]}$. In addition, the OAJEM also assigns exposure to other recognized occupational risk factors for asthma. Each matrix cell contains a yes or no indication of exposure, favouring specificity over sensitivity as jobs are classified as exposed only if the probability of exposure is expected to be high for a considerable number of subjects in that job. Seven of the protein-derived HMW included in the OAJEM are agents causing sensitization through an IgEmediated mechanism. These agents are classified in a hierarchical scheme with some specific allergens nested in the larger groups: latex, flour, other plant antigens (derived from plants); rodents and livestock, fish and shellfish (derived from animals); arthropods or mites; and bioaerosols. These agents are known to produce asthma through an IgE mediated mechanism. The OAJEM also evaluates low molecular weight agents that include a variety of organic and inorganic compounds that have not been consistently associated with an IgE-mediated mechanism such as isocyanates, metal fumes and wood dusts, bioaerosols including moulds and endotoxins and four mixed environments that have been associated with asthma (metal working fluids, textile and agricultural settings). Finally, the OAJEM includes three wide groups of (mainly irritating) agents that may be considered low risk factors for (occupational) asthma.

Estimates of exposure to asthma causing agents were derived for each job held by study subjects and individual indices of exposure were created by integration over the whole occupational history of each case and control. Exposed individuals were defined taking into account 5 years of lag for high molecular weight exposures; for cases, exposures occurring in the last 5 years before the diagnosis were not considered, for controls, the lag was based on the interview date. We calculated the duration of occupational exposure using the total time of exposure among jobs excluding the 5 years previous to the date of diagnosis/interview. A five-year exposure lag was applied under the assumption that very recent exposures cannot be the causes of the lymphoma.

\subsection{Statistical analysis}

Unconditional logistic regression was used to assess the risk of lymphoma in relation to ever exposure to high molecular weight agents. Odds ratios (OR) and the corresponding 95\% confidence intervals (CI) for all lymphomas and lymphoma subtypes were estimated adjusting for age (in quartiles), sex and study centre. Alternative analysis was done with further adjustment for potential confounders, we estimated the risk of lymphoma including educational level (as marker of socioeconomic status), smoking, and also other occupational exposures evaluated by the matrix (low risk exposures and other high risk exposures as low molecular weight, mixed exposures, bioaerosols, drugs, and irritants).

Specific allergens exposure was evaluated for all lymphomas and B-cell lymphoma and Hodgkin lymphoma. In order to assess the duration-response relationship, we evaluated cumulative years of exposure to high molecular weight agents during occupational history. Generalized additive models (GAM) were applied to exposed individuals to examine the linearity of the duration-response effect; since the 
Espinosa, A., Zock, J.P., Benavente, Y., Boffetta, P., Becker, N., Brennan, P., Cocco, P., Foretova, L., Maynadié, M., Staines, A., Nieters, A., Kogevinas, M., Sanjose, S. de. Occupational exposure to immunologically active agents and risk for lymphoma: the European Epilympa 7 case-control study. Cancer Epidemiology: 2013, 37(4), 378-384

relationship was non-linear, we analyzed duration of exposure using years of exposure dichotomized at the median (8 years) for exposed individuals.

Several sensitivity analyses were done. To ensure that the estimates were not affected by excluding exposures occurred in the last 5 years, we performed an additional analysis excluding those individuals that had been exposed only in the 5 previous years to diagnosis or interview. We also estimated the risk of lymphoma without taking into account the 5 year lag assumption, and additionally we tested a ten-year

exposure lag. For Hodgkin lymphoma, we randomized a 1:1 matched case-control and applied conditional logistic regression to asses the impact of the unequal distribution of age between Hodgkin lymphoma cases and controls; for this analysis, controls were matched to Hodgkin cases by centre, age and sex. To make sure that the risk estimates were robust and not dependent on a specific country, we evaluated the risk of lymphoma excluding the countries one by one. Furthermore, we tested the interaction between country and exposure to HMW agents through likelihood-ratio test and evaluated also the heterogeneity between country-specific estimates using Isquared measure ${ }^{[22]}$. As countries did not present heterogeneity, neither interaction between country and exposure was found, we present the results of the pooled analyses. Effect modification by asthma was assessed through a stratified analysis by asthma status and also using likelihood-ratio test comparing models with additive and interaction terms.

The level of significance was set at 0.05 and all tests were two-sided. All analyses were performed using statistical package Stata version 12.1 (StataCorp LP, Texas, USA).

\section{RESULTS}

Table 1 describes the characteristics of the study population by case/control status and major lymphoma subtypes. Controls and all lymphoma cases were similar concerning age, sex and educational level. Hodgkin lymphoma cases were significantly $(p<0.0001)$ younger (mean $=39$ years, $s d=15.3)$ than controls (mean $=56$ years, $\mathrm{sd}=15.7)$ and had higher educational level $(p<0.0001)$. Controls were more likely to have self-reported asthma ( $8 \%$ and $6 \%$ of controls and cases, respectively). Concerning other occupational exposures, Hodgkin lymphoma cases were less often exposed to low risk exposures and other high risk exposures ( $p=$ 0.008 and $p<0.0001$, respectively).

Odds ratios for all lymphoma and major lymphoma subtypes related to occupational exposure to high molecular weight agents are shown in ${ }^{\text {Table } 2}$. Subjects exposed to HMW agents had a risk of the order of 0.9 for most types of lymphoma, although conventional levels of statistical significance were only reached for Hodgkin lymphoma. A 12\% decreased risk was found for all lymphoma (OR, 0.88; 95\% CI, 0.74-1.05) and a similar estimation was found for B-cell lymphoma category (OR, 0.91; 95\% CI, 0.76-1.09), while lower risk was observed for Hodgkin lymphoma (OR, 0.62; 95\% CI, 0.40-0.98). Additional adjustment for other potential confounders did not change the observed risk estimates for high molecular weight agents. The analysis by country did not show any significant association (Fig. 2), although the direction was consistent across countries except for Germany, that 
Espinosa, A., Zock, J.P., Benavente, Y., Boffetta, P., Becker, N., Brennan, P., Cocco, P., Foretova, L., Maynadié, M., Staines, A., Nieters, A., Kogevinas, M., Sanjose, S. de. Occupational exposure to immunologically active agents and risk for lymphoma: the European Epilympa 7 case-control study. Cancer Epidemiology: 2013, 37(4), 378-384

showed a positive OR for all lymphoma and B-cell lymphoma; and for Spain, that showed a positive OR for Hodgkin lymphoma, being consistent with the preliminary analysis of the Spanish part of the Epilymph study ${ }^{[15]}$.

\section{[TABLE 2]}

An evaluation of duration of exposure did not show differences in risk when examining exposures in two groups classified by the median (Table 3) or when evaluating tertiles of exposure (not shown). Evaluation of age at first exposure did not show differences in risk of lymphoma. Results for specific allergens are also shown in Table 3. Only one B-cell lymphoma case and no controls had occupational exposure to fish enzymes and this category was excluded from the table. We evaluated separate associations for the six remaining HMW agents and ORs were consistent with the results for exposure to any allergens, except for exposure to plant antigens where a non-significant increased risk was assessed for all lymphoma (OR,

1.85; 95\% CI, 0.77-4.43) and for B-cell lymphoma (OR, 1.81; 95\% CI, 0.72-4.54).

Exposure to latex antigens showed a statistically significant decreased risk for lymphoma (OR, 0.74; 95\% CI, 0.55-0.99) and stronger inverse risk was obtained for the association between latex exposure and Hodgkin lymphoma (OR, 0.32; 95\% CI, $0.15-0.69)$.

\section{[TABLE 3]}

Occupational exposure to HMW agents showed a non-significant increased risk of asthma (OR, 1.15; 95\% CI, 0.85-1.57) and asthmatics individuals showed a significantly decreased risk of lymphoma (OR, 0.74; 95\% CI, 0.59-0.93). We performed sensitivity analyses excluding asthmatics individuals and results where consistent, for all lymphoma we observed a non-significant decreased risk of $13 \%$ in exposed individuals (OR, 0.87; 95\% CI, 0.73-1.04), and the significance for Hodgkin lymphoma remained when asthmatic individuals were excluded (OR, 0.63; 95\% CI, 0.40-0.99).

Only 10 cases and 12 controls were excluded when we performed sensitivity analysis to ensure that exposures occurring in the 5 previous years to the diagnostic/interview did not affect to the estimates, and results remained the same. Similar results were also obtained when the lag period was extended to 10 years. Results for Hodgkin lymphoma risk were similar when we conducted an age and sex matched casecontrol, showing a stronger risk reduction (OR, 0.46; 95\% CI, 0.28-0.77). As we had seen in the country-specific estimates, exposure to HMW agents showed opposite direction of risk for all lymphoma and B-cell lymphoma in Germany, while an increased OR was observed in Spain for Hodgkin lymphoma. In the sensitivity analysis excluding the centres one by one, we obtained a significant risk reduction for all lymphoma when Germany was excluded (OR, 0.78; 95\% CI, 0.63-0.96), and similarly for B-cell lymphoma (OR, 0.79; 95\% CI, 0.63-0.99). For Hodgkin 
Espinosa, A., Zock, J.P., Benavente, Y., Boffetta, P., Becker, N., Brennan, P., Cocco, P., Foretova, L., Maynadié, M., Staines, A., Nieters, A., Kogevinas, M., Sanjose, S. de. Occupational exposure to immunologically active agents and risk for lymphoma: the European Epilympa 7 case-control study. Cancer Epidemiology: 2013, 37(4), 378-384

lymphoma, a stronger risk reduction was obtained when we excluded Spain form the pooled analysis (OR, 0.46; 95\% CI, 0.27-0.80).

\section{DISCUSSION}

Our results suggest that exposure to HMW agents may moderately modulate the risk of lymphoma, being consistent with previous findings in the literature showing a lower risk among individuals with a medical history of allergies and allergic asthma and among those with high IgE levels at the time of diagnosis ${ }^{[2]}$ and [11] . Our data based on lifetime occupational exposure are in agreement with a temporal relationship as exposures occurred at least 5 years before diagnosis. We did not observe a trend of lower lymphoma risks with increasing number of years exposed; the reduced risk was mainly seen among those exposed less than 8 years. Almost all lymphoma subtypes showed an OR less than one but were only statistically significant for Hodgkin lymphoma and for B-cell lymphoma among those exposed less than 8 years in a consistent manner across the different countries. Focusing on the HMW specific allergens, this risk reduction of lymphoma in exposed individuals was mostly due to exposure to animal antigens, flour-associated antigens, and latex antigens and was statistically significant for exposure to latex for all lymphoma and for Hodgkin lymphoma.

Several potential limitations of our study should be discussed. The study is based in hospital and population controls depending on the country and we found a low response rate in the population based studies. Hospital case-control studies are more likely to show a lower OR associated to medical conditions. To address a potential selection bias due to the inclusion of hospital controls that could be more likely to suffer asthma than cases, we excluded controls who were hospitalized due to respiratory diseases. Further, there were no major differences in the analysis when hospital and population based studies were compared. For Hodgkin lymphoma, which is our main finding, results were comparable in hospital-based and populationbased centres. Results were mostly consistent between countries; differences were observed for B-cell lymphoma in Germany and for Hodgkin lymphoma in Spain. These differences could not be explained by a variation in the age distribution of the cases between countries, nor by a variation in the prevalence of exposure. Finally, the small numbers of some specific lymphoma types do not allow making inferences for some specific types.

HMW agents that are known to stimulate the immune system through an IgE mediated pathway were associated with a moderately decreased risk for B-cell lymphoma. The mechanism of antibody-dependent hypersensitivity and asthma is complex. HMW agents are complete antigens and cross-link with surface-bound IgE, leading to a cascade of events and eventually to an inflammatory response. Several inflammatory mediators, e.g. IL3, IL4 and IL5 cytokines, $\beta$-chemokines, are involved in this process. The mechanism underlying the association between exposure to HMW agents and lymphoma may be directly related to the nature of Th2 type responses. The fact that the potential protective effect of several IgE related exposures (i.e. asthma, atopy, occupational exposures or IgE levels) is seen in a wide range of lymphoma subtypes irrespective of aggresivity of the subtype and prior to 
Espinosa, A., Zock, J.P., Benavente, Y., Boffetta, P., Becker, N., Brennan, P., Cocco, P., Foretova, L., Maynadié, M., Staines, A., Nieters, A., Kogevinas, M., Sanjose, S. de. Occupational exposure to immunologically active agents and risk for lymphoma: the European Epilympa 7 case-control study. Cancer Epidemiology: 2013, 37(4), 378-384

treatment, could be interpreted as a generic trigger linked to the Th1/2 equilibrium rather than a result of a biased approach of the epidemiological studies.

Epidemiological evidence indicates that IgE mediated conditions such as asthma and allergy are inversely associated with lymphoma risk. In the pooled analysis of InterLymph Consortia, including over 13,000 cases of NHL and over 16,000 controls, a significant reduction of NHL risk was observed for history of allergy (OR, 0.80; 95\% CI, 0.68-0.94). In this study the protective effect of asthma was largely explained by the joint presentation of other allergic conditions ${ }^{[2]}$.

Breen et al. ${ }^{[23]}$ evaluated several B-stimulatory cytokines and markers of Immune activation including IgE levels in HIV patients prior to NHL development. The authors identified increased levels of Il-6, sCD27 and sCD30 more than 3 years before the diagnosis of systemic NHL. No variations were observed however for IgE and sCD23, the low affinity receptor for IgE, suggesting that these latter ones were not in the pathway of HIV-related NHL.

Assessment of occupational exposures using a job exposure matrix (JEM) has been applied in many community-based epidemiological studies to assign cumulative exposure to workers. Since variability in exposure within job categories is typically not accounted for, this has been shown to lead frequently to an underestimation of the risk due to non-differential exposure misclassification. In addition, the validity of exposure assessment depends on the quality of the underlying information on occupational histories derived from interviews. The application of the specific occupational asthma JEM has been shown in large cohort studies to predict occurrence of asthma risk among exposed workers ${ }^{[24]}$. The advantage of using this matrix is the evaluation of a group of agents that occur in a variety of jobs. Data collection of lifetime history provided in the face to face interview and the posterior assignment of the job codes and of the specific exposure using the matrix is complex. The use of a labour-intensive expert assessment by industrial hygienists to reevaluate specific exposures may lead to more valid exposure assignments with a higher specificity.

The association of lymphoma risk with IgE or other immunoglobulin levels as well as the association with clinical conditions such as allergy or asthma could alternatively be due to reverse causation through suppression of the immunologic response to allergens among lymphoma patients. In this respect it has been proposed that allergy and lymphoma could develop in parallel through similar immune-related mechanisms ${ }^{[25]}$. The approach followed in this study overcomes this problem since the evaluation of immune response is done through the estimation of lifetime exposure to known occupational chemical agents that affect this response and that are associated with asthma. The application of a 5-year lag in the evaluation of exposure further minimizes the potential for any reverse association of disease on the exposure. However, we cannot rule out misclassification of the exposure. This should not have a biased effect but could have resulted in attenuation of the exposure-response relationships and hence a lower power to detect a true association. Fig. 3 despites in a very simplified manner the interrelationship of the potential mechanisms that may lead to lower risk of lymphoma and the potential alternative explanations as counterpart. 
Espinosa, A., Zock, J.P., Benavente, Y., Boffetta, P., Becker, N., Brennan, P., Cocco, P., Foretova, L., Maynadié, M., Staines, A., Nieters, A., Kogevinas, M., Sanjose, S. de. Occupational exposure to immunologically active agents and risk for lymphoma: the European Epilympa 7 case-control study. Cancer Epidemiology: 2013, 37(4), 378-384

\section{[FIGURE 3]}

In conclusion, we observed a moderately reduced risk between occupational exposure to HMW agents and lymphoma risk, this reduction was found for most lymphoma subtypes, although statistical significance was reached only for Hodgkin lymphoma. This finding is plausible when interpreted in the light of the role of immunological factors in lymphomagenesis. Some inconsistencies in results, the small number of exposed cases, and the retrospective nature of the investigation prevent drawing conclusions on the causal nature of the association. We expect our results to stimulate further epidemiologic and mechanistic research in this field.

\section{CONFLICT OF INTEREST}

All authors declare no conflict of interest.

\section{REFERENCES}

[1] H. Hjalgrim, E.A. Engels Infectious aetiology of Hodgkin and non-Hodgkin lymphomas: a review of the epidemiological evidence Journal of Internal Medicine, 264 (2008), pp. 537548

[2] C.M. Vajdic, M.O. Falster, S. de Sanjose, O. Martínez-Maza, N. Becker, P.M. Bracci et al. Atopic disease and risk of non-Hodgkin lymphoma: an InterLymph pooled analysis Cancer Research, 69 (2009), pp. 6482-6489

[3] E.A. Holly, C. Lele, P.M. Bracci, M.S. McGrath Case-control study of non-Hodgkin's lymphoma among women and heterosexual men in the San Francisco Bay Area, California American Journal of Epidemiology, 150 (1999), pp. 375-389

[4] P. Vineis, L. Miligi, P. Crosignani, A. Fontana, G. Masala, O. Nanni et al. Delayed infection, family size and malignant lymphomas Journal of Epidemiology \& Community Health, 54 (2000), pp. 907-911

[5] W. Cozen, J.R. Cerhan, O. Martinez-Maza, M.H. Ward, M. Linet, J.S. Colt et al. The effect of atopy, childhood crowding, and other immune-related factors on non-Hodgkin lymphoma risk Cancer Causes and Control, 18 (2007), pp. 821-831

[6] S.K. Dikalioti, E.T. Chang, N. Dessypris, C. Papadopoulou, N. Skenderis, A. Pourtsidis et al. Allergy-associated symptoms in relation to childhood non-Hodgkin's as contrasted to Hodgkin's lymphomas: a case-control study in Greece and meta-analysis European Journal of Cancer, 48 (2012), pp. 1860-1866

[7] J.R. Cerhan, Z.S. Fredericksen, A.H. Wang, T.M. Habermann, N.E. Kay, W.R. Macon et al. Design and validity of a clinic-based case-control study on the molecular epidemiology of lymphoma International Journal of Molecular Epidemiology and Genetics, 2 (2011), pp. 95-113

[8] A.M. Linabery, A.M. Jurek, S. Duval, J.A. Ross The association between atopy and childhood/adolescent leukemia: a meta-analysis American Journal of Epidemiology, 171 (2010), pp. 749-764

[9] B.F. Skinnider, T.W. Mak The role of cytokines in classical Hodgkin lymphoma Blood, 99 (2002), pp. 4283-4297

[10] D.T. Umetsu, J.J. McIntire, O. Akbari, C. Macaubas, R.H. DeKruyff Asthma: an epidemic of dysregulated immunity Nature Immunology, 3 (2002), pp. 715-720 
Espinosa, A., Zock, J.P., Benavente, Y., Boffetta, P., Becker, N., Brennan, P., Cocco, P., Foretova, L., Maynadié, M., Staines, A., Nieters, A., Kogevinas, M., Sanjose, S. de. Occupational exposure to immunologically active agents and risk for lymphoma: the European Epilympa 7 case-control study. Cancer Epidemiology: 2013, 37(4), 378-384

[11] L. Ellison-Loschmann, Y. Benavente, J. Douwes, E. Buendia, R. Font, T. Alvaro et al. Immunoglobulin E levels and risk of lymphoma in a case-control study in Spain Cancer Epidemiology, Biomarkers \& Prevention, 16 (2007), pp. 1492-1498

[12] M. Melbye, K.E. Smedby, T. Lehtinen, K. Rostgaard, B. Glimelius, L. Munksgaard et al. Atopy and risk of non-Hodgkin lymphoma Journal of the National Cancer Institute, 99 (2007), pp. 158-166

[13] S.M. Kennedy, N. Le Moual, D. Choudat, F. Kauffmann Development of an asthma specific job exposure matrix and its application in the epidemiological study of genetics and environment in asthma (EGEA) Occupational and Environmental Medicine, 57 (2000), pp. 635-641

[14] J.-L. Malo, M. Chan-Yeung Agents causing occupational asthma Journal of Allergy and Clinical Immunology, 123 (2009), pp. 545-550

[15] M. Kogevinas, J.-P. Zock, T. Alvaro, M. Garcia-Villanueva, E. Domingo-Domenech, S. Kennedy et al. Occupational exposure to immunologically active agents and risk for lymphoma Cancer Epidemiology, Biomarkers \& Prevention, 13 (2004), pp. 1814-1818

[16] M.C. Mirabelli, J.-P. Zock, A. D’Errico, M. Kogevinas, S. de Sanjosé, L. Miligi et al. Occupational exposure to high molecular weight allergens and lymphoma risk among Italian adults Cancer Epidemiology, Biomarkers \& Prevention, 18 (2009), pp. 2650-2654

[17] J.J. Turner, L.M. Morton, M.S. Linet, C.A. Clarke, M.E. Kadin, C.M. Vajdic et al. Interlymph hierarchical classification of lymphoid neoplasms for epidemiologic research based on the WHO classification (2008): update and future directions Blood, 116 (2010), pp. e90-e98

[18] S.H. Swerdlow, E. Campo, N.L. Harris, E.S. Jaffe, S.A. Pileri, H. Stein et al. WHO classification of tumours of haematopoietic and lymphoid tissues IARC, Lyon (2008)

[19] J. Fortuny, S. de Sanjosé, N. Becker, M. Maynadié, P.L. Cocco, A. Staines et al. Statin use and risk of lymphoid neoplasms: results from the European Case-Control Study Epilymph Cancer Epidemiology, Biomarkers \& Prevention, 15 (2006), pp. 921-925

[20] H. Besson, P. Brennan, N. Becker, S. De Sanjosé, A. Nieters, R. Font et al. Tobacco smoking, alcohol drinking and Hodgkin's lymphoma: a European multi-centre case-control study (Epilymph) British Journal of Cancer, 95 (2006), pp. 378-384

[21] ILO: International Labor Organisation International standard classification of occupations (Revised Edition 1968)ILO, Geneva (1981)

[22] J.P.T. Higgins, S.G. Thompson Quantifying heterogeneity in a meta-analysis Statistics in Medicine, 21 (2002), pp. 1539-1558

[23] E.C. Breen, S.K. Hussain, L. Magpantay, L.P. Jacobson, R. Detels, C.S. Rabkin et al. Bcell stimulatory cytokines and markers of immune activation are elevated several years prior to the diagnosis of systemic AIDS-associated non-Hodgkin B-cell lymphoma Cancer Epidemiology, Biomarkers \& Prevention, 20 (2011), pp. 1303-1314

[24] M. Kogevinas, J.-P. Zock, D. Jarvis, H. Kromhout, L. Lillienberg, E. Plana et al. Exposure to substances in the workplace and new-onset asthma: an international prospective population-based study (ECRHS-II) Lancet, 370 (2007), pp. 336-341

[25] H. Wang, T.L. Diepgen Is atopy a protective or a risk factor for cancer? A review of epidemiological studies Allergy, 60 (2005), pp. 1098-1111 
Espinosa, A., Zock, J.P., Benavente, Y., Boffetta, P., Becker, N., Brennan, P., Cocco, P., Foretova, L., Maynadié, M., Staines, A., Nieters, A., Kogevinas, M., Sanjose, S. de. Occupational exposure to immunologically active agents and risk for lymphoma: the European Epilympa 7 case-control study. Cancer Epidemiology: 2013, 37(4), 378-384

\section{TABLES AND FIGURES}

Fig. 1. :Study population flow diagram.

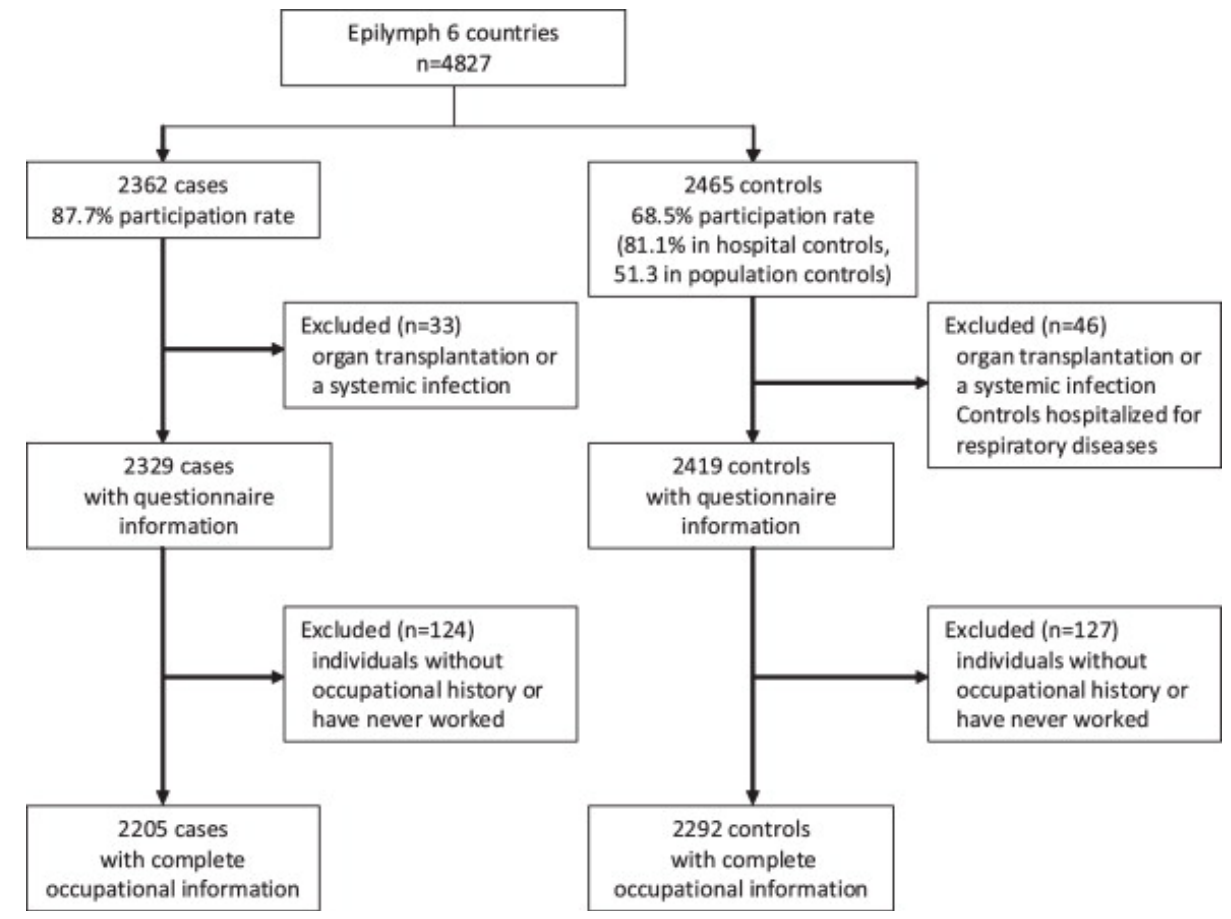

Table 1. Characteristics of the study population.

\begin{tabular}{|c|c|c|c|c|c|}
\hline & \begin{tabular}{|l|} 
Controls \\
$(n=$ \\
$2296)$
\end{tabular} & $\begin{array}{l}\text { All } \\
\text { lymphoma } \\
(\mathbf{n}=2205)\end{array}$ & $\begin{array}{l}\text { B-cell } \\
\text { lymphoma } \\
(\mathrm{n}=1696)\end{array}$ & $\begin{array}{l}\text { Hodgkin } \\
\text { lymphoma } \\
(\mathrm{n}=299)\end{array}$ & $\begin{array}{l}\text { T-cell } \\
\text { lymphoma } \\
(\mathrm{n}=125)\end{array}$ \\
\hline \multicolumn{6}{|l|}{ Country } \\
\hline Spain & $546(23.8)$ & $534(24.2)$ & $424(25.0)$ & $56(18.7)$ & 42 (33.6) \\
\hline France & $253(11.0)$ & $281(12.7)$ & $227(13.4)$ & $30(10.0)$ & $16(12.8)$ \\
\hline Germany & $694(30.2)$ & $681(30.9)$ & $524(30.9)$ & $100(33.4)$ & $34(27.2)$ \\
\hline Italy & $297(12.9)$ & $228(10.3)$ & $190(11.2)$ & $22(7.4)$ & $12(9.6)$ \\
\hline Ireland & 204 (8.9) & $196(8.9)$ & 134 (7.9) & $33(11.0)$ & 11 (8.8) \\
\hline $\begin{array}{l}\text { Czech } \\
\text { Republic }\end{array}$ & 302 (13.2) & 285 (12.9) & 197 (11.6) & 58 (19.4) & $10(8.0)$ \\
\hline \multicolumn{6}{|l|}{ Sex } \\
\hline Female & $\begin{array}{l}1026 \\
(44.7)\end{array}$ & 946 (42.9) & 730 (43.0) & $135(45.2)$ & 48 (38.4) \\
\hline $\begin{array}{l}\text { Age, mean } \\
\text { (sd) }\end{array}$ & 56 (15.7) & 57 (15.7) & 60 (13.6) & 39 (15.3) & 55 (15.0) \\
\hline \multicolumn{6}{|c|}{$\begin{array}{l}\text { Educational } \\
\text { level }\end{array}$} \\
\hline Low & $\begin{array}{l}1023 \\
(44.6)\end{array}$ & 998 (45.3) & 816 (48.1) & 81 (27.1) & 66 (52.8) \\
\hline
\end{tabular}


Espinosa, A., Zock, J.P., Benavente, Y., Boffetta, P., Becker, N., Brennan, P., Cocco, P., Foretova, L., Maynadié, M., Staines, A., Nieters, A., Kogevinas, M., Sanjose, S. de. Occupational exposure to immunologically active agents and risk for lymphoma: the European Epilympla 7 case-control study. Cancer Epidemiology: 2013, 37(4), 378-384

\begin{tabular}{|c|c|c|c|c|c|}
\hline & $\begin{array}{l}\text { Controls } \\
(\mathrm{n}= \\
2296)\end{array}$ & $\begin{array}{l}\text { All } \\
\text { lymphoma } \\
(\mathbf{n}=2205)\end{array}$ & $\begin{array}{l}\text { B-cell } \\
\text { lymphoma } \\
(\mathrm{n}=1696)\end{array}$ & $\begin{array}{l}\text { Hodgkin } \\
\text { lymphoma } \\
(\mathbf{n}=299)\end{array}$ & $\begin{array}{l}\text { T-cell } \\
\text { lymphoma } \\
(n=125)\end{array}$ \\
\hline Medium & $952(41.5)$ & $885(40.1)$ & $647(38.1)$ & $157(52.5)$ & $44(35.2)$ \\
\hline High & $321(14.0)$ & $322(14.6)$ & $233(13.7)$ & $61(20.4)$ & $15(12.0)$ \\
\hline \multicolumn{6}{|c|}{ Ever asthma diagnosis } \\
\hline Yes & $192(8.4)$ & $143(6.5)$ & $113(6.7)$ & $18(6.0)$ & $7(5.6)$ \\
\hline \multicolumn{6}{|c|}{ High molecular weight exposure } \\
\hline Exposed & $354(15.4)$ & $304(13.8)$ & $248(14.6)$ & $26(8.7)$ & $18(14.4)$ \\
\hline \multicolumn{6}{|c|}{ Other asthma high risk exposures } \\
\hline Exposed & $\begin{array}{l}1126 \\
(49.0)\end{array}$ & 1067 (48.4) & 846 (49.9) & $114(38.1)$ & $70(56.0)$ \\
\hline \multicolumn{6}{|c|}{ Asthma low risk exposures } \\
\hline Exposed & $\begin{array}{l}1081 \\
(47.1)\end{array}$ & $1067(48.4)$ & $854(50.4)$ & $116(38.8)$ & $58(46.4)$ \\
\hline
\end{tabular}

Numbers (\%) are given, unless otherwise indicated.

Table 2: Associations between exposure to high molecular weigh agents and lymphoma risk in the Epilymph study. Odds ratios (OR) and 95\% confidence intervals (CI).

\begin{tabular}{|l|l|l|l|}
\hline & $\mathbf{n}$ & $\begin{array}{l}\mathbf{n}(\%) \\
\text { Exposed }\end{array}$ & OR (95\% CI)a \\
\hline Controls & 2296 & $354(15.4 \%)$ & 1 (Reference) \\
\hline All lymphoma & 2205 & $304(13.8 \%)$ & $0.88(0.74,1.05)$ \\
\hline B-cell lymphoma & 1696 & $248(14.6 \%)$ & $0.91(0.76,1.09)$ \\
\hline DLBCL and similar NHL & 501 & $75(15.0 \%)$ & $0.93(0.70,1.23)$ \\
\hline B CLL-SLL and similar NHL & 395 & $60(15.2 \%)$ & $1.03(0.75,1.41)$ \\
\hline Multiple myeloma & 265 & $37(14.0 \%)$ & $0.86(0.59,1.26)$ \\
\hline Follicular NHL & 239 & $37(15.5 \%)$ & $0.89(0.60,1.30)$ \\
\hline Marginal zone B-cell lymphoma & 98 & $16(16.3 \%)$ & $0.95(0.54,1.68)$ \\
\hline Mantle cell lymphoma & 65 & $5(7.7 \%)$ & $0.58(0.23,1.51)$ \\
\hline LPL and similar NHL & 43 & $6(14.0 \%)$ & $0.83(0.34,2.04)$ \\
\hline Splenic marginal zone B-cell lymphoma & 38 & $8(21.1 \%)$ & $1.08(0.48,2.46)$ \\
\hline Precursor B NHL & 37 & $4(10.8 \%)$ & $0.71(0.24,2.09)$ \\
\hline Hairy cell leukaemia & 15 & $0(0.0 \%)$ & n.e. \\
\hline Hodgkin lymphoma & 299 & $26(8.7 \%)$ & $0.62(0.40,0.98)$ \\
\hline Classical HL & 275 & $23(8.4 \%)$ & $0.58(0.36,0.94)$ \\
\hline Non-classical HL & 24 & $3(12.5 \%)$ & $1.34(0.37,4.87)$ \\
\hline T-cell lymphoma & 125 & $18(14.4 \%)$ & $0.97(0.57,1.66)$ \\
\hline Mycosis T-cell NHL & 35 & $9(25.7 \%)$ & $1.83(0.81,4.12)$ \\
\hline Other T-cell NHL ${ }^{b}$ & 90 & $9(10.0 \%)$ & $0.64(0.31,1.31)$ \\
\hline
\end{tabular}


Espinosa, A., Zock, J.P., Benavente, Y., Boffetta, P., Becker, N., Brennan, P., Cocco, P., Foretova, L., Maynadié, M., Staines, A., Nieters, A., Kogevinas, M., Sanjose, S. de. Occupational exposure to immunologically active agents and risk for lymphoma: the European Epilympa case-control study. Cancer Epidemiology: 2013, 37(4), 378-384

NHL: non-Hodgkin lymphoma; DLBCL: diffuse large B-cell lymphoma; CLL: chronic lymphocytic leukaemia; SLL: small lymphocytic lymphoma; LPL: lymphoplasmacytic lymphoma; n.e.: non-estimable.

${ }^{A}$ Odds ratio and 95\% confidence interval adjusted for age (categorical), sex and country.

${ }^{B}$ Includes: precursor T-cell NHL, cutaneous T-cell NHL and other T-cell NHL.

Fig. 2: Country-specific associations and pooled estimates between exposure to high molecular weight agents and risk of lymphoma; ${ }^{\mathrm{a}} \mathrm{B}$-cell lymphoma includes: DLBCL and similar NHL, B CLL-SLL and similar NHL, multiple myeloma, follicular NHL, marginal zone B-cell lymphoma, mantle cell lymphoma, LPL and similar NHL, splenic marginal zone B-cell lymphoma, precursor B NHL, hairy cell leukaemia; ${ }^{\mathrm{b}} \mathrm{T}$ cell lymphoma includes: precursor T-cell NHL, mycosis T-cell NHL, cutaneous Tcell NHL and other T-cell NHL.
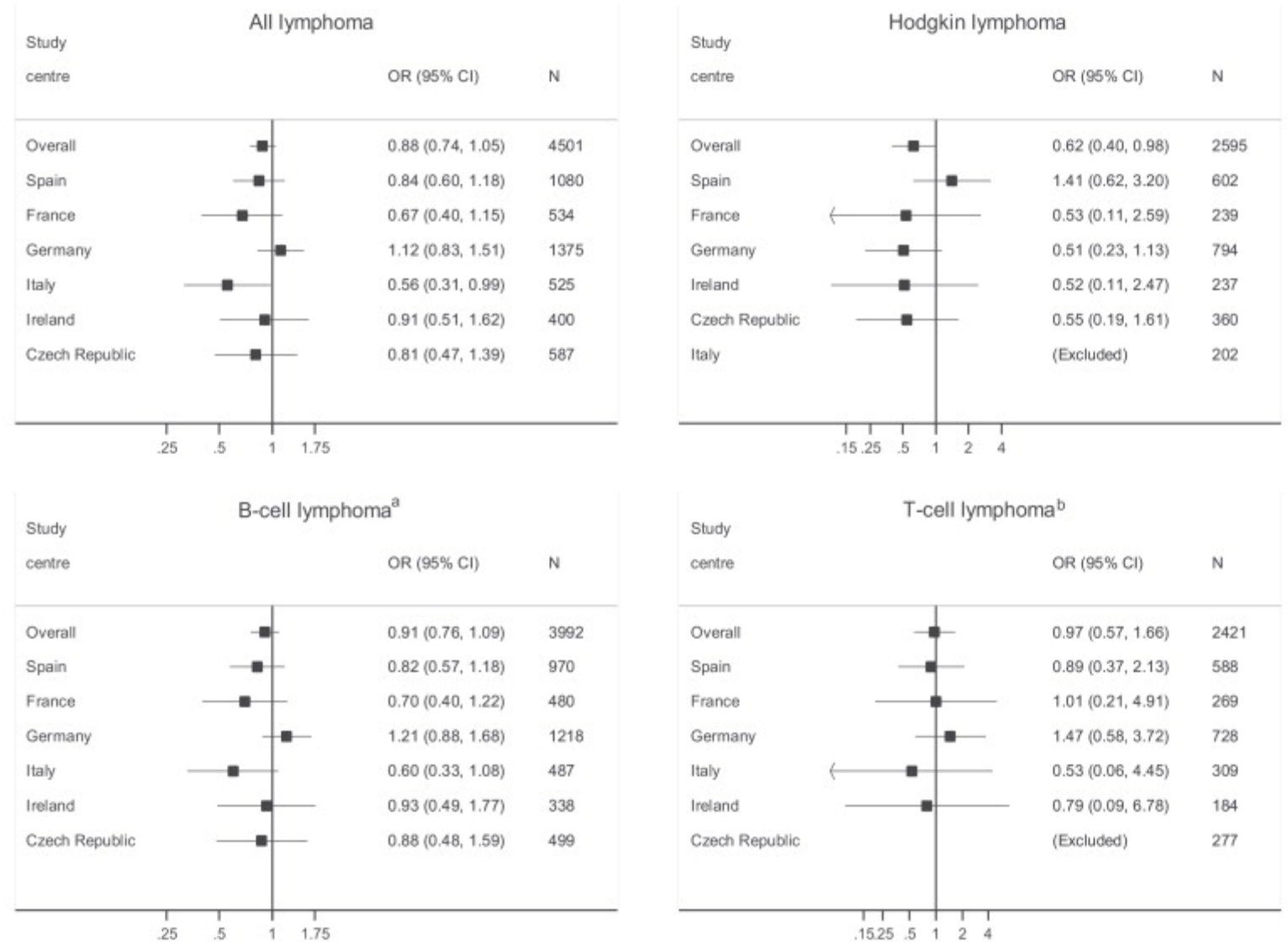
Espinosa, A., Zock, J.P., Benavente, Y., Boffetta, P., Becker, N., Brennan, P., Cocco, P., Foretova, L., Maynadié, M., Staines, A., Nieters, A., Kogevinas, M., Sanjose, S. de. Occupational exposure to immunologically active agents and risk for lymphoma: the European Epilympl- 7 case-control study. Cancer Epidemiology: 2013, 37(4), 378-384

Table 3: Associations between duration and specific type of exposure to high molecular weight (HMW) agents and lymphoma.

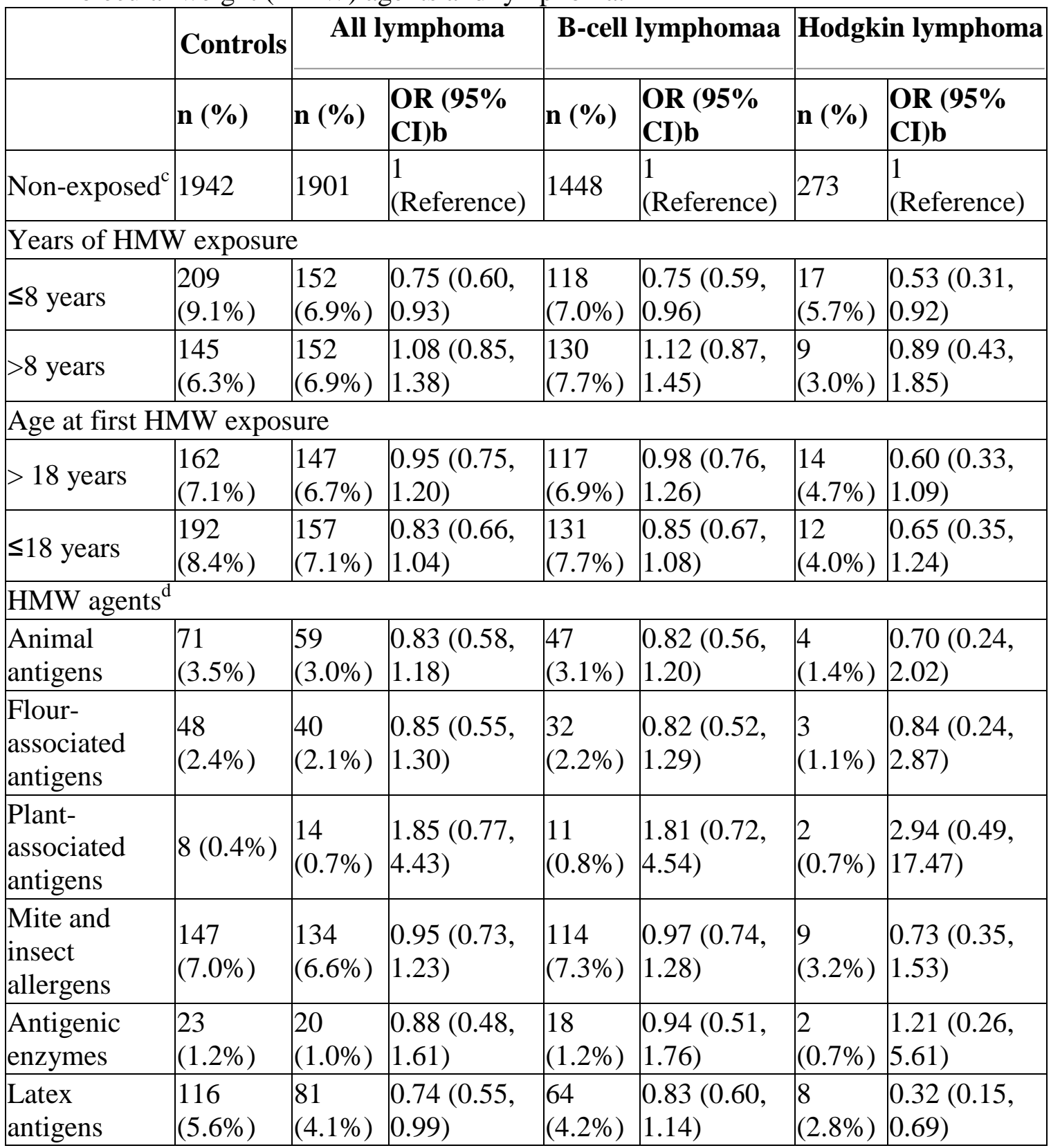

A B-cell lymphoma includes: DLBCL and similar NHL, B CLL-SLL and similar NHL, multiple myeloma, follicular NHL, marginal zone B-cell lymphoma, mantle cell lymphoma, LPL and similar NHL, splenic marginal zone B-cell lymphoma, precursor B NHL, hairy cell leukaemia.

${ }^{\mathrm{B}}$ Odds ratio and 95\% confidence interval adjusted for age (categorical), sex and country.

${ }^{\mathrm{C}}$ Reference group for all models.

${ }^{\mathrm{D}}$ Non-mutually exclusive agents (one subject can be in more than one group). 
Espinosa, A., Zock, J.P., Benavente, Y., Boffetta, P., Becker, N., Brennan, P., Cocco, P., Foretova, L., Maynadié, M., Staines, A., Nieters, A., Kogevinas, M., Sanjose, S. de. Occupational exposure to immunologically active agents and risk for lymphoma: the European Epilympa 7 case-control study. Cancer Epidemiology: 2013, 37(4), 378-384

Fig. 3. : Outline of the potential link between IgE mediated immune response and lymphoma risk and potential biases. IgE mediated conditions such asthma and allergy have been found to be inversely associated with lymphoma risk [11]; this association might be also attributed to a reverse causation when evaluated retrospectively. The evaluation of occupational exposures may be non-differentially misclassified with an attenuation of the observed association [15]. Diagnosis of allergic diseases may condition the selection of an occupation.

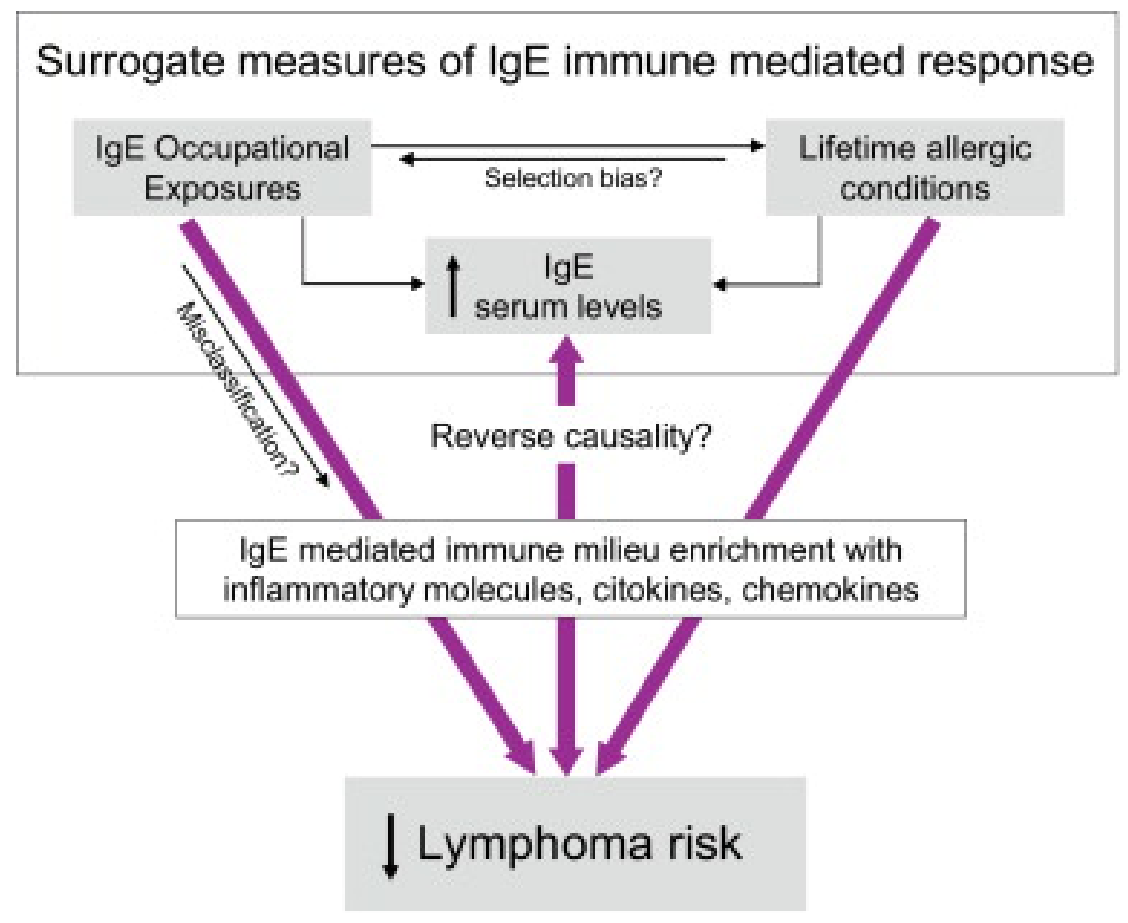

